April - 2009

Regional Focus Issue: Bridge over Troubled Waters Cengiz Hakan Aydin and Yoram EshetAlkalai, IRRODL Regional Editors for the Middle East

\title{
Information and Communication Technology (ICT) in the Service of Multiculturalism
}

\author{
Elaine Hoter \\ Talpiot College of Education, Holon \\ Miri Shonfeld \\ Kibbutzim College of Education, Tel Aviv
}

\author{
Asmaa Ganayim \\ Al-Qasemi College of Education, Baka al-Gharbiya
}

\begin{abstract}
This paper presents an online inter-group contact hypothesis (OICH) model, developed within the Israel education system, whereby online and distance learning (ODL) is used in the service of multiculturalism. The goal is to build bridges among secular and religious Arabs and Jews in Israel based on small multicultural groups and collaborative learning through effective use of the Internet and other cutting-edge information technologies. The model expands the contact hypothesis (which holds that under the right conditions contact could reduce bias between groups) to a model for online collaboration. It adds the gradual development of contact between the groups by progressing from individual asynchronous textual communication to individual synchronous audio communication combined with collaborative asynchronous communication to collaborative synchronous communication and finally to face-to-face communication.
\end{abstract}

Keywords: Multiculturalism; online learning; ICT; Contact Hypothesis; teacher education; collaboration; technology; team teaching and learning; CMC; OICH; ODL

\section{Introduction}

In our global reality, living together and accepting differences while building on commonalities has become crucial to everyday life. Yet in many places in the world, galloping globalization is accompanied by a growing trend toward cultural, national, and religious individuation and separatism. 
In Israel, which is beset by inter-cultural tensions and political enmities, differences, rather than similarities, are often in the forefront of public discourse and in the minds of many Israelis. Moreover, Israelis of diverse religions and backgrounds, who live in the same area or neighborhoods in mixed cities, often experience great difficulty in communicating with each other or have little or no notion as to who their neighbors are. They are separated not geographically but most often psychologically by prejudices and a host of stereotypical beliefs (Ghanem, 2001; Ganayem, 2005). Thus, inter-cultural dialogue is essential in a country like Israel, which comprises a broad range of ethnic groups and religions, all of which share a small patch of land. It is vital that groups living in such close proximity meet, identify, and build on commonalities, rather than dwell on differences and areas of potential conflict (Smooha, 1989).

Mirroring the diverse religious and cultural streams, most sectors in Israel have their own school curriculum and often their own teacher training institutes, for example, the Jewish sector, which is divided into secular and religious streams, and the Arab sector, which includes Moslem Arabs, Christian Arabs, Druze and Bedouins, both religious and secular. Consequently, in the normal course of things, students from different educational streams seldom have the occasion to meet or interact. As a result, in this conflict-ridden society, in which daily occurrences and events often serve to further divide rather than to unite, mutual stereotypes are reinforced.

Indeed, the protracted Israeli-Palestinian conflict, most particularly since the second Intifadah (2000), has exacerbated mutual fears, suspicions, and hatred within Israel itself. Among religious Arabs and orthodox Jews, the wall of preconceived notions, mistrust, and lack of readiness to even listen to the other side appears to be even greater. Both sides tend to ascribe demonic characteristics to each other, viewed as God-given, i.e., absolute and immutable; and therefore, they are often opposed to attempts to engage in dialogue as if the very exchange might be misinterpreted or used by the other side as a sign of legitimization of its positions.

Teacher education colleges are potentially major agents of social change and dialogue among cultures in that they are charged with the important task of training future teachers, who in turn have an impact on future generations of students. Yet students in teacher colleges are, on the whole, not exposed to courses on multiculturalism or to exchanges with sectors and groups other than their own. This is true not only between Jews and Arabs but also between secular and religious Jews. As a result, when these students become teachers, they (wittingly or unwittingly) tend to reflect, and thereby perpetuate, their own stereotypical views of the "other" among the children with whose education they are entrusted.

The technological reality of the 21st century provides the tools to combat the perpetuation of these stereotypes. It allows for in-depth acquaintance with other cultures based on common universal values in addition to the unique values of each culture, thus developing a more open, understanding, and respectful dialogue.

In this environment, the Center for Multiculturalism and Technology was established in early 2005 by the writers, who are the heads of the respective IT departments of the Jewish secular Kibbutz College of Education, the orthodox Jewish Talpiot College of Education, and the Arab- 
Islamic Al-Qasemi College of Education, with the support of the principals of these three colleges. The aim of the Center is to develop and implement an innovative learning and teaching model that connects cultures and ethnic groups through IT while enhancing IT skills and their creative application to teaching and learning. The model used for this aim, entitled the online inter-group contact hypothesis (OICH) model (see Figure 1), enables faculty, pre-service teachers, in-service teachers, and ultimately students to teach and learn advanced Internet technologies while facilitating first-hand acquaintance with various cultures based on shared universal values that complement the unique values of each culture.

Applying this model in the classroom, the first online course from the three participating teaching colleges opened in the 2005/6 academic year with a total of 45 participants and three lecturers. In each subsequent year, three additional colleges joined, one per sector, bringing the number of participating colleges in 2007 to nine and tripling the annual number of participating students. All participating students received a special certificate that will enable them to teach in school projects.

This article describes the OICH model, where ICT is used in the service of multiculturalism to build bridges, based on small multicultural groups and collaborative learning, among secular and religious Arabs and Jews in Israel through effective use of the Internet and other cutting-edge information technologies.

\section{Theoretical Background}

Much of the research on connecting among different cultures is based on the contact hypothesis (Allport, 1954), which lays down the conditions for successful contact between two or more groups. Allport claims that knowledge of differences between groups is not in itself enough to stop prejudice. In order to reduce prejudice and bias, it is necessary to become directly acquainted with people of the other culture/sect, etc., and his hypothesis stipulates a number of conditions that need to be fulfilled in order to reach this goal: equal-group status within the situation; common goals; intergroup cooperation; and institutional support. Under these conditions, participants in information exchange and intergroup interaction "increase their knowledge of the outgroup and reduce intergroup anxiety, which in turn broadens the perceptual field to allow impressions of outgroups to become more accurate and more favorable” (Stephan \& Stephan, 1984). Thus, previous stereotyping and prejudice towards the other culture is reduced. In fact, although studies claim that indeed there is a change in how an individual relates to another individual from a different cultural group, this change in attitude does not always lead to a change in the individual's bias against the entire group. In order for there to be a change in global attitudes, there must be carefully controlled conditions (Brown \& Wade, 1987; Hewstone \& Brown, 1986; Riordan \& Ruggiero, 1980; Scarberry, Ratcliff, Lord, Lanicek, \& Desforges, 1997).

Pettigrew and Tropp (2000) stipulate that one of the basic requirements for successful contact between cultures is cooperation and collaboration. In addition, they claim that bias can be reduced without applying all of Allport's conditions. They claim that the contact itself in some cases could be sufficient for lasting bias reduction and that it generalizes beyond the individual to the larger 
group. However, they show that the more conditions applied, the more the bias is reduced, and with a lasting effect. In Pettigrew and Tropp (2004), they refine their conditions and require that contact should be cooperative rather than competitive, between partners of equal status, between groups rather than individuals, long-term rather than short-term, supported by the institution, and capable of leading to the development of a "super-ordinate identity," i.e., one that transcends local, regional, or national identity.

There are many problems involved with applying the contact hypothesis through face-to-face contact (Amichai-Hamburger \& McKenna, 2006; Shonfeld, Ganayam, \& Hoter, 2006). They include the logistics of group meetings, the need to meet with another group from a nearby or easily accessible geographical location, and growing transportation costs. It is difficult to meet the condition of equality of status in a face-to-face meeting where people are sensitive to dress codes and subtle cues of status (Hogg, 1993). Another issue that appears in the research is one of anxiety at the prospect of a face-to-face meeting (Stephan \& Stephan, 2001). These problems can be overcome by using online communication among the groups.

Interaction, which can progress from written correspondence to aural/oral contact to video and finally to face-to-face meetings, has been put forward to build up the trust among groups through collaboration and cooperation in joint tasks (Amichai-Hamburger \& McKenna, 2006; Shonfeld, Ganayam, \& Hoter, 2006; Shonfeld et al., 2008).

Research on adapting the contact hypothesis to virtual rather than real contact began in the mid1990s. Sundberg (2001) suggests that geographical distance lessens feelings of threat and anxiety. Postmes, Spears, and Lea $(1998,2002)$ show that group interaction raises participants' understanding of the outgroup, i.e., the group outside of their own culture, thus reducing previous bias.

A number of computer-mediated communication (CMC) projects have been carried out among diverse populations, specifically populations in conflict, based on the contact hypothesis. Probably the best documented one is Dissolving Boundaries, carried out from 1999 to 2008 between Northern Ireland and the Republic of Ireland (Austin, 2006). This project brings together online students and pupils from the different religious sectors of Northern Ireland and the Republic of Ireland for joint study projects. The research concludes that sustained curricular and social interaction has an effect on childrens' perceptions of each other and that the effect is most marked between two schools, one on each side of the border.

In Israel, efforts to use CMC between Arab and Jewish populations have met with inconsistent results. Mollov and Lavie (2001) and Mollov (2006) examined discussions that focused specifically on Jewish and Islamic religious practices through email exchanges between Israelis and Palestinians. They concluded that a one-to-one religious dialogue was a means for building Israeli-Palestinian understanding. However, group encounters that focused on political concerns did not result in reducing biases (Ellis \& Maoz, 2007; Maoz \& Ellis, 2001). 
For CMC interaction to be successful, it is important to incorporate different learning models in collaborative learning. According to Ligorio and Veermans (2005), research data confirm that international Web-based interaction can work effectively only "when meaningful pedagogical models are implemented." Austin and Anderson (2008) claim that a new paradigm is emerging that can bring together insights from both social learning theories in education and insights from social psychology. Additional research shows that asynchronous instruction has to be carefully structured to assist student learning: discussion topics should be well-designed, and there should be frequent e-moderator or instructor input and feedback (Salmon, 2004; Ellis \& Hafner, 2003).

Concerning the issue of how important it is to initially see (or not see) the other group members, Lea, Spears, and de Groot (2001) claim that that it is advantageous not to see the other group members. They claim that the lack of visually individuating cues in CMC diverts individuals' attention from distinctive characteristics of group members. This depersonalizes perceptions and allows for identification with the prominent group.

The social identity model of deindividuation effects (SIDE) (Reicher, Spears, \& Postmes, 1995) applies social identity theory to CMC by focusing on the consequences of visual anonymity for identification processes online. Social identity theory claims that people see themselves more as part of a group than as individuals; also, they view their partners to be equivalent and interchangeable with other in-group members. Intergroup identification exaggerates perceptions of similarity between oneself and other in-group members and magnifies perceived differences between self and out-groups (Tajfel \& Turner, 1986)

The building of trust is a crucial component in a multicultural CMC course (Walther \& Bunz, 2005; Walther, 2008). Krebs, Hobman, and Bordia (2006) demonstrated that the use of CMC lowered the lack of trust among people of different ages relative to face-to-face groups. Using experimental groups with a variety of diverse characteristics among their members, they found a positive association between birthplace dissimilarity and trust in CMC groups, but not in face-toface groups. Smith (2008) uses a psychodynamic, constructivist perspective to analyze online collaborative groups, showing how past conscious and unconscious trust experiences can greatly influence current trust issues. According to Salmons (2008), the development of trust is gradual and moves through different stages of interaction and collaboration, starting from dialogue to peer review to parallel collaboration to sequential collaboration and finally to synergistic collaboration.

\section{The OICH Model}

The online inter-group contact hypothesis $(\mathrm{OICH})$ model is based on an extension of the contact hypothesis (Allport, 1954). Its aim is to adapt the original contact hypothesis for online connections between groups in conflict. The model is applicable to various levels of professional/project-oriented collaboration among culturally diverse groups: academic staff at teaching colleges; trainees in the teaching colleges; teachers in schools, who are program graduates; and pupils in schools who collaborate on educational projects. 
The components of the model are illustrated in Figure 1.

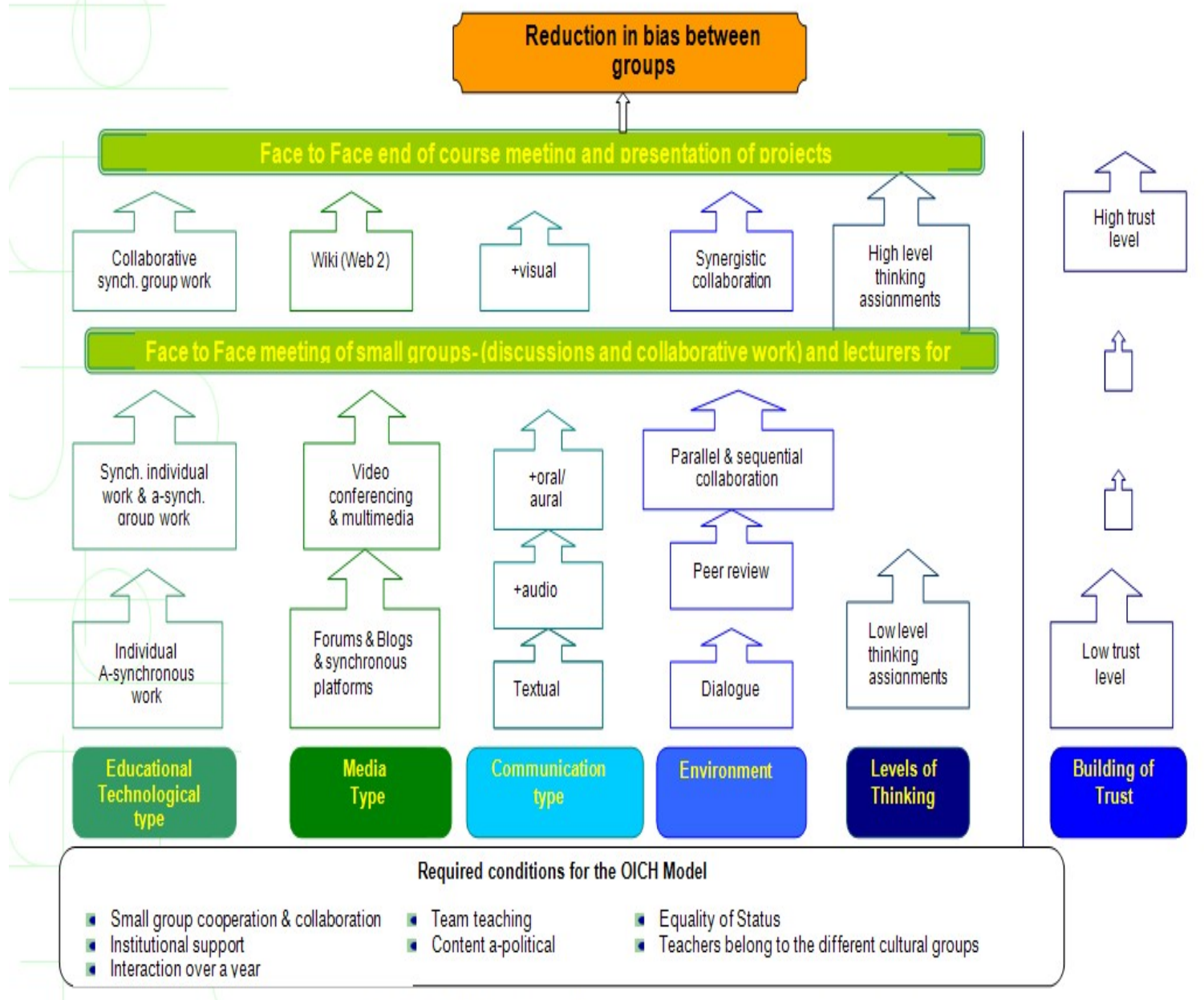

Figure 1. The OICH Model: online inter-group contact hypothesis

In order for the model to work, the project must meet a number of conditions, which are outlined below:

- be fully supported by each participating institution,

- involve collaboration among groups rather than among individuals,

- deal with general subjects and not with conflicts,

- be based on a need for participant collaboration rather than competition,

- ensure participants have equal status,

- progress gradually over a period of at least one year, beginning with exchanges via the Internet followed by text and voice exchange and finally, after a positive online experience, by face-to-face encounters among the partners, and 
- employ teachers who themselves come from the different cultural groups and who "team teach" the course in a collegial environment.

The multi-collegial IT course offered by the Center annually since 2005 uses this model in a unique course that offers Israelis from diverse religions and backgrounds an advanced Internet learning environment, which focuses on computerized tools and online teaching methods (including forums, blogs, wikis, film editing programs, and more). Teacher trainees learn about applications of technology in teaching, and they practice these within the framework of a given topic or discipline of their choice.

As shown in Figure 1, courses based on this model are delivered online synchronously and asynchronously based on team teaching and group projects. The teams and the groups include participants from the three different cultures in a cooperative, non-competitive environment. The communication among the groups begins with text-based forums, but as the course progresses, the online educational platforms enable audio communication. Initially, there is a lecture with two-way communication between the lecturer and the trainees. Later, the groups begin to communicate directly through audio programs. After a few months of meetings through the Internet almost every week, the students meet either through a video conference or face-to-face. At the end of the academic year, the students meet to socialize and present their group project exhibitions. By this point, the groups' interests have become paramount and the cultural differences have become irrelevant.

Teamwork is part of the ideology and is modeled through team teaching by the culturally diverse course instructors. The participants work in small multicultural groups; each participant comes from a different college; and each group includes two trainees from each of the participating sectors (i.e., secular Jewish, orthodox Jewish, and Arab). Their lecturers also become partners in the projects. The participants receive an individual as well as a group grade in which both cooperation and collaboration are taken into consideration. This is explained for each assignment in the rubric for the activity. Thus, participants understand the importance of collaborating and cooperating with their partners in order to achieve the maximum grade. The collaborative Internet teaching and learning includes reading an article, the collaborative creation of online and multimedia educational materials, management of and participation in discussions, and, finally, online instruction.

Course content areas reflect subjects taught within the formal education system, for example, science, the environment, special education, nutrition and health, mathematics, current events, drama, music, etc. In all these areas, trainees collaborate in creating an online unit that includes materials they have developed throughout the course. The tasks are relevant to teacher education and to students' needs, and most require high-level thinking. In each of the chosen areas, students receive a list of assignments calling for the use of different media and skills. To assess the trainees' work, a clear structured rubric for each assignment is created. Examples of assigned tasks include the following:

- development of an educational game, 
- creation of a video clip,

- involvement in Internet research, including use of various databanks,

- searching for relevant articles and discussing these articles and other resources in the field,

- participation in activities incorporating understanding and the implications of safe and secure Internet use,

- reflection via personal blogs,

- building of treasure hunts and Web quests,

- working and collaborating on a wiki.

The course is based on online units where part of the work is asynchronous, coupled with synchronous lessons that take place every two to three weeks. Its unique format allows trainees to learn and interact at their convenience in a Learning Management System (HighLearn), which includes learning materials, tasks, and discussion forums. The communication component provides a virtual café, where participants can get help and support on group assignments from their peers.

Small multicultural groups of trainees use an online forum to discuss their work developing learning units on a specific educational subject of their choice, and they provide each other with formative evaluation.

\section{Course Satisfaction}

In 2007-8, such a course was held among nine different colleges. At the end of the course, a short questionnaire was administered to find out the level of satisfaction with the course. Seventy-one students completed the questionnaire and wrote a short reflection in the blog they had created during the course. In addition, in the face-to-face meeting at the end of the course, they were videotaped while speaking about the course and their work in a multicultural environment.

Some results from the questionnaire are presented in Table 1.

Table 1

Course Satisfaction

\begin{tabular}{|l||l|l|}
\hline Question & $\begin{array}{l}\text { On a scale of 1-5 } \\
\text { (5 is high) }\end{array}$ & SD \\
\hline $\begin{array}{l}\text { Satisfaction with the method of learning and its } \\
\text { effectiveness }\end{array}$ & 3.17 & SD $=1.2$ \\
\hline Satisfaction with the tasks & 3.79 & SD $=0.95$ \\
\hline Interest in learning about other cultures and religions & 4 & SD $=0.97$ \\
\hline
\end{tabular}


Satisfaction from studying in a multicultural environment $\mid$\begin{tabular}{l|l}
3.76 & $\mathrm{SD}=1.18$
\end{tabular}

In their reflections, many students noted that one of the reasons for the success of the course was the extensive collaboration among the instructors. S. explained the modeling she viewed and experienced:

The excellent team teaching encouraged the collaborative learning in the groups between the students and this is the reason for the success of the course.

At the year-end, face-to-face meeting of the project participants, students spoke about their mutual exposure to the other cultures and the changes in attitudes this elicited. One Arab student illustrated the empathy generated among women in her group:

It became apparent that our relations had become 'normal', when last night, after completing our joint project on the phone, we complained to each other about our husbands' lack of consideration.

An orthodox Jewish student from one of the settlements added this remark:

This coming year, I will begin teaching....and when I use the word 'Arab' in my class, it will sound different than it would have before the course.

Another student offered this comment:

My hope is that this is the start of something new...that we will succeed in showing everyone that little by little we can move ahead toward constructive dialogue.

As the course progressed, many participants emphasized the importance of initial contact through the Internet, rather than face-to-face meetings, as this allowed them to feel less threatened, imbued them with a sense of equal status, and enabled them to be more open and frank with each other:

There is almost no subject that can't be dealt with online... and because the subject is a loaded one, the geographic barrier enables a measure of emotional restraint, allowing us to approach difficult emotional issues in a rational manner.

It is precisely because of the enmity between Jews and Arabs....that the Internet can serve as an effective means for multi-cultural exchange...it obviates face-toface friction... barriers fall away, enabling a productive discussion. 
I don't think I'd be able to say what I've just said at a face-to-face conference...the screen made it easier for me to express my thoughts and feelings.

The formal questionnaires yielded numerous remarks and insights in response to the question, "What did you learn about different cultures?” These included students' feelings that they had more in common with each other than anticipated and observations by Arab students that they were pleasantly surprised to be treated as equals:

I learnt that there is no discrimination in this course. Everyone has an equal opportunity to express themselves and to participate. The lecturer relates to each student's forum posting in an equal manner.

Program participants had to overcome a number of cultural differences and obstacles, such as problems of language, differing study habits, inter-cultural competitiveness, and ideological and psychological barriers. For example, it was difficult for some in the initial group of orthodox Jewish male students to accept women in their group. Some, because of their beliefs, did not attend the face-to-face meeting, as it included both men and women. Secular Jews were anxious about collaborating with both orthodox Jewish students and Arab students, who look different and espouse different religious beliefs. For the Arab students, the barrier was one of language and fear of facing inequality in the group. When questioned about the difficulties they encountered in the course, responses ranged from insufficient knowledge of the Hebrew language to technological backgrounds of varying levels to the learning pace and style of the diverse student group members.

\section{Lessons Learned}

The issue of the language of instruction is important in this type of course, where not all students' first language is identical. Pre-course questionnaires showed that the Arab-Israeli students preferred Hebrew as the language of the course rather than English. However, the proficiency level among the populations is diverse. While the Arab-Israeli students wrote the same number of messages in the forums as the native-speaking Jewish-Israeli, they differed in length, in complexity of language, and in complexity of content. To combat this problem, a new course rule was set up whereby no attention would be given to spelling or grammar errors by other participants. This, we believed, would allow the Arab-Israeli students to be less inhibited and more willing to write freely.

Collaborative learning needs a long process of gradual group work. And, in the end, not all groups manage to work collaboratively. In order to improve the groups' chances for collaborative learning, we held training sessions for the teaching staff on collaborative learning and eventually added more stages for the assignments in the program.

Some subjects chosen by the groups proved to be too provocative and led to heated discussions on political issues. One such topic was history, where, of course, each culture came with a 
different narrative. We decided to eliminate this topic from the list. Another seemingly apolitical subject, sports, proved to be very political. In these situations, where subjects became provocative, it was left to the teacher responsible for each group to veto problematic sub-topics.

Another issue which proved to be problematic concerned one of the groups chosen to represent the Jewish religious colleges. The group was made up of male students studying religious and Biblical studies. This group refused to attend the face-to-face meetings because of the dress code of the non-religious female participants. We decided in the future to work with only mixed or female groups from the religious Jewish sectors because we see the face-to-face meetings as an integral and important component in our model.

\section{Conclusion}

The model developed and the results presented from the course based on the model show that structured ICT intervention can reduce bias, stigmas, and ethnic prejudice among prospective teachers. The OICH model not only builds bridges among cultures but also promotes advanced uses of technology and the Internet for trainees' self-improvement and pedagogical goals. The model is unique in the way it promotes the gradual use of educational technology and types of communication while at the same time creating a collaborative environment, a high level of trust, and high-level thinking through the use of such tools as blogs and wikis.

The initial evaluation of the course reveals a high level of satisfaction on the part of participating students. More research is needed to understand how the use of various technologies can not only improve the ICT abilities of the participants but also improve the relationship among participants by reducing bias and stereotyping of other groups.

The next immediate step is the implementation of the model in the school system, so the project can have a significant, societal ripple effect. In this way, future teachers will apply their newlyacquired technological skills to their teaching, while introducing their newly developed multicultural worldview to their pupils, who are from diverse backgrounds, religions, and geographic locations, and thus impact the broad Israeli pupil population.

The model can also be adapted to countries facing multicultural challenges. As well, it is suitable for students from elementary school to colleges in addition to adult learners.

Finally, project feedback indicates that attractive content of intrinsic interest and relevance to teachers' and students' needs motivates participants to open their minds to new technologies and integrate them into their teaching while opening their hearts to colleagues from other cultural groups. 


\section{References}

Allport, G. W. (1954). The nature of prejudice. Cambridge, MA: Addison-Wesley.

Amichai-Hamburger, Y. \& McKenna, K. Y. A. (2006). The contact hypothesis reconsidered: Interacting via the Internet. Journal of Computer-Mediated Communication, 11(3), 825 843.

Austin, R. (2006). The role of ICT in bridge-building and social inclusion: Theory, policy and practice issues. European Journal of Teacher Education, 29(2), 145-161.

Austin, R. \& Anderson, J. (2008). Building bridges online: Issues of pedagogy and learning outcomes in intercultural education through citizenship. International Journal of Information and Communication Technology Education, 4(1), 86-94.

Brown, R. J. \& Wade, G. S. (1987). Superordinate goals and intergroup behaviour: The effect of role ambiguity and status on intergroup attitudes and task performance. European Journal of Social Psychology, 17(2), 131-142.

Ellis, D. G., \& Moaz, I. (2007). Online argument between Israeli Jews and Palestinians. Human Communication Research, 33(3), 291-309.

Ellis, T. \& Hafner, J. (2003). Engineering an online course: Applying the 'secrets' of computer programming to course development. British Journal of Educational Technology, 34(5), 639-650.

Ganayem, A. (2005, 16-18 November). Internet use among the Arab society in Israel. Paper presented at the World Summit on the Information Society, Tunisia.

Ganayem, A., Shonfeld, M., \& Hoter, E. (2007, February 20). Faculty gets connected to multiculturalism. Paper presented at the Chais Conference on Instructional Technologies: Learning in the Technological Era, The Open University of Israel, Raanana (in Hebrew).

Ghanem, A. (2001). The Palestinian-Arab minority in Israel, 1948-2000: A political study. Albany, NY: State University of New York Press.

Hewstone, M. R. C., \& Brown, R. J. (1986). Contact is not enough: An intergroup perspective on the contact hypothesis. In M. R. C. Hewstone \& R. J. Brown (Eds.), Contact and conflict in intergroup encounters (pp. 1-44). Oxford: Blackwell.

Hogg, M. A. (1993). Group cohesiveness: A critical review and some new directions. European Review of Social Psychology, 4, 85-111. 
Hoter, E. (2001). A model for learning how to teach advanced literacy skills via computer mediated communication. The Hebrew University, Jerusalem. http://www.talpiot.ac.il/elaine/index.htm

Hoter, E., Ganayem, A., \& Shonfeld, M. (2007). Building bridges between cultures in conflict. Paper presented at WiAOC2007.

Krebs, S. A., Hobman, E. V., \& Bordia, P. (2006). Virtual teams and group member dissimilarity: Consequences for the development of trust. Small Group Research, 37(6), 721-741.

Lea, M., Spears, R., \& de Groot, D. (2001). Knowing me, knowing you: Anonymity effects on social identity processes within groups. Personality and Social Psychology Bulletin, 27(5), 526-537.

Ligorio, B., \& Veermans, M. (2005). Perspectives and patterns in developing and implementing international web-based collaborative learning environments. Computers and Education, 45(3), 271-275.

Maoz, I., \& Ellis, D. G. (2001). Going to ground: Argument in Israeli-Jewish and Palestinian encounter groups. Research on Language \& Social Interaction, 34(4), 399-419.

Mollov, B. (2006, June). Results of Israeli and Palestinian student interactions in CMC: An analysis of attitude changes toward conflicting parties. Paper presented at the annual meeting of the International Communication Association, Dresden, Germany.

Mollov, B., \& Lavie, C. (2001). Culture, dialogue, and perception change in the IsraeliPalestinian conflict. The International Journal of Conflict Management, 12(1), 69-87.

Pettigrew, T. F., \& Tropp, L. R. (2000). Does intergroup contact reduce prejudice? Recent metaanalytic findings. In S. Oskamp (Ed.), Reducing prejudice and discrimination (pp. 93114). Mahwah, NJ: Erlbaum.

Pettigrew, T. F., \& Tropp, L. R. (2004). A meta-analytic test of intergroup contact theory (unpublished manuscript). University of California, Santa Cruz, CA.

Postmes, T., Spears, R., \& Lea, M. (1998). Breaching or building social boundaries? SIDE-effects of computer-mediated communication. Communication Research, 25(6), 689-715.

Postmes, T., Spears, R., \& Lea, M. (2002). Intergroup differentiation in computer-mediated communication: Effects of depersonalization. Group Dynamics: Theory, Research, and Practice, 6(1), 3-16.

Reicher, S. D., Spears, R., \& Postmes, T. (1995). A social identity model of deindividuation phenomena. European Review of Social Psychology, 6, 161-198. 
Riordan, C., \& Ruggiero, J. (1980). Producing equal-status interracial interaction: A replication. Social Psychology Quarterly, 43(1), 131-136.

Salmon, G. (2004). E-moderating: The key to teaching \& learning online (2nd ed.). New York: Routledge-Farmer.

Salmons, J. (2008). From dialogue to synergy: Building collaborative relationships. Paper presented at the Online Conference on Technology, Multi-Culturalism and Collaboration. http://tak.macam.ac.il/eng/2008/S2_1.asp

Scarberry, N. C., Ratcliff, C. D., Lord, C. G., Lanicek, D. L., \& Desforges, D. M. (1997). Effects of individuating information on the generalization part of Allport's contact hypothesis. Personality and Social Psychology Bulletin, 23(12), 1291-1299.

Shonfeld, M. (2005). The impact of an online conference in education: A case study. Unpublished doctoral dissertation, Nova Southeastern University.

Shonfeld, M., Ganayem, A., \& Hoter, E. (2006). Constructing bridges between cultures in conflict through an online teacher education course. Paper presented at the International Conference on the Role of ICT in Bridge-building and Social Inclusion, University of Ulster, Ireland.

Shonfeld, M., Hoter, E., Ganayem, A., Sloma, N., \& Wated, H. (2008). Pride and prejudice: How can ICT intervention reduce bias, stigmas and ethnic prejudice among prospective teachers? In K. McFerrin, et al. (Eds.), Proceedings of Society for Information Technology and Teacher Education International Conference (pp. 4328-4330). Chesapeake, VA: AACE.

Shonfeld, M., Hoter, E., \& Ganayem, A. (2006). Shake up and wake up the faculty: A model for intervention in technology diffusion. In C. Crawford, et al. (Eds.), Proceedings of Society for Information Technology and Teacher Education International Conference 2006 (pp. 1335-1342). Chesapeake, VA: AACE.

Smooha, S. (1989). Arabs and Jews in Israel: Conflicting and shared attitudes in a divided society. Boulder: Westview Press.

Smith, R. O. (2008). The paradox of trust in online collaborative groups. Distance Education, 29(3), 325-340.

Stephan, W. G., \& Stephan, C. W. (1984). The role of ignorance in intergroup relations. In N. Miller \& M. B. Brewer (Eds.), Groups in contact: The psychology of desegregation (pp. 229-255). New York: Academic Press. 
Stephan, W. G., \& Stephan, C. W. (2001). Improving intergroup relations. Newbury, CA: Sage.

Sundberg, P. A. (2001, June 25-27). Building positive attitudes among geographically-diverse students: The project I-57 experience. Paper presented at the National Educational Computing Conference, NECC 2001: Building on the Future, Chicago, IL.

Tajfel, H., \& Turner, J. C. (1986). The social identity theory of inter-group behavior. In S. Worchel \& W. G. Austin (Eds.), Psychology of intergroup relations (pp. 7-24). Chicago: Nelson-Hall.

Walther, J. B. (2008, July 6-9). Computer-mediated communication and relationships within ethnopolitical contexts. Paper presented at the Communication across Borders conference, Interdisciplinary Center, Herzliya, Israel.

Walther, J. B., \& Bunz, U. (2005). The rules of virtual groups: Trust, liking, and performance in computer-mediated communication. Journal of Communication, 55(4), 828-846.

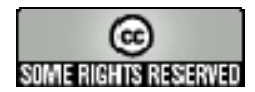

